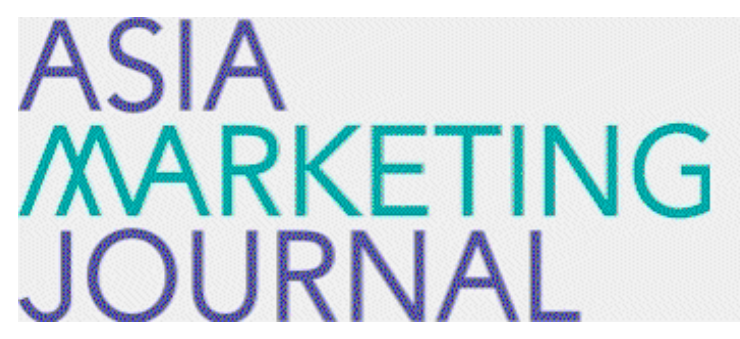

ASIA MARKETING JOURNAL

Volume 4 | Issue 3

Article 2

$9-1-2002$

\title{
신제품 개발팀의 특성이 신제품 개발 성과에 미치는 영향
}

Hyung Jun Kim

Follow this and additional works at: https://amj.kma.re.kr/journal

Part of the Marketing Commons

\section{Recommended Citation}

Kim, Hyung Jun (2002) "신제품 개발팀의 특성이 신제품 개발 성 과에 미치는 영향," Asia Marketing Journal: Vol. 4 : Iss. 3 , Article 2.

Available at: https://doi.org/10.53728/2765-6500.1089

This Article is brought to you for free and open access by Asia Marketing Journal. It has been accepted for inclusion in Asia Marketing Journal by an authorized editor of Asia Marketing Journal. 


\title{
신제품 개발팀의 특성이 신제품 개발 성과에 미치는 영향 : 조직학습 이론을 중심으로
}

\section{The Impacts of NPD Team's Characteristics on the Performance of NPD Process \\ : Based on the Organizational Learning Theory}

\author{
김형준(전주대학교 경영학부 조교수) \\ bizguruejeonju. ac. kr
}

본 연구는 신제품 개발 과정을 시장지식과 기술지식을 흡수, 활용하는 일종의 학습
(learning)과정으로 인식하고 신제품 개발 팀을 하나의 학습 조직(learning organization)으로
파악하여 개발 팁의 학습 능력과 학습 능력을 지원할 수 있는 팁의 구조/분위기적인 톡성이
신제품 경쟁우위의 달성에 중요한 요인임을 제시하고자 하였다. 신제품의 시장 성과는
신제품 경쟁우위(품질 우수성, 시간 효율성)의 확보에서 비롯되며 이러한 경쟁우위에
영향을 미치는 조직 학습의 요인은 마케팅 부서와 R\&D부서의 정보 공유 행동과 조직기억의
활용도에 영향울 받는다. 또한 신제품 개발팀의 자율적인 분위기 및 신뢰의 분위기는
조직학습올 원할하게 수행할 수 있는 요인이 될 뿐만 아니라 신제품 개발과정의 시간
효율성을 달성합에 있어 중요한 요인이 된다.

• 논문접수 : 02.09 게재확정 : 02.11 


\section{1. 서 론}

제품 수명주기의 단축, 경쟁의 범세계화, 기술변화속도의 격변과 같은 기업 환경의 변화로 인하여 기업의 신제품 개발의 동인이 중가하고 있으며 이에 따라 신제품 개발을 효과적/효율적으로 수행하고 이를 통한 기업의 마케텅 성과률 높이는 것이 중요한 마케팅의 목적이 되었다. 기업의 판매에서 신제품이 차지하는 비중은 중가하고 있으나 신제품 성공률은 그리 높지 않은 것으로 조사되고 있다. 신제품 실패에 따른 기업의 타격은 기업의 존립을 위협할 수도 있는 것이다. 많은 경우에 있어 신제품 개발에 따르는 비용으로 인하여 잘못된 신제품 개발은 상당한 매몰비용(sunk cost)올 부담하여야 하며 기술적인 폐쇄 (technology lock-in)로 인하여 경쟁기업과 기술격차도 발생하게 되는 것이다.

신제품이 시장에서 성공할 수 있는 조건은 무엇인가? 신제품의 성공요인에 대한 연구는 상당히 많으며 개별적인 연구들은 시장에서의 신제품 성공요인을 매우 다양하게 제시하고 있다.(Cooper, 1979; Cooper \& Kleinschmidt, 1994; Maidique \& Zirger, 1984, von Hippel, 1988; Song \& Parry, 1997 etc.). Cooper(1979)는 신제품 성공 요인을 경쟁 환경, 기업의 내적 환경, 신제품 개발과정, 제품의 경쟁우위의 네 가지 요인으로 분류하고 있으며 Montoya-Weiss \& Calantone(1994)는 47개의 신제품 개발 연구에 대한 메타분석을 통하여 신제품의 성과 요인올 전략적 요인, 개발과정 요인, 시장 환경 요인, 조직 요인의 네 가지 범주로 나누어 18개의 세부적인 성공요인을 체시한다. Song \& Parry(1997)의 연구에서는 경쟁환경, 마케텅 시너지, 기술적 시너지, 기능간 통합, 경쟁과 시장 인텔리전스, 마케팅 숙련도, 기술 숙련도, 제품 경쟁우위의 8 가지로 분류하고 있다. 국내 연구의 경우 기업환경, 기업 자원, 신제품 프로젝트의 신제품 개발노력과 신제품의 특성이 기술적인 성공과 시장의 요구 충족에 영향을 미치고 최종적으로 상업적인 성공과 실패에 영향요인으로 작용한다고 주장하고 있으며(김 훙범, 1986) 윤 태석(1992)의 연구에서는 시장 안정성, 상대적 경쟁력, 기업자원이 제품의 특성과 마케텅 노력에 영향을 미치고 마케팅 노력의 결과 신제품의 성과가 달성된다는 실중적인 결과를 제시하고 있다. 신제품 개발의 상황적인 맥락이나 신제품 성공의 국가간 산업간의 차이를 제시하는 연구(eg: 임종원과 김기찬, 1989 ; Yap \& Souder, 1994; Souder \& Song, 1997 등)에서도 신제품 성공 요인을 다양하게 제시하고 있다.

기존의 연구를 정리하여 보면 신제뚬 성공 요인은 환경적인 요인과 신제품 개발 과정 (process) 요인과 제품 경쟁우위 요인으로 구분할 수 있다. 환경적인 요인은 시장환경이나 경쟁환경이 얼마나 유리하게 작용하고 있는가와 같은 기업 외부요인과 기업 전반적인 보유자원, 문화와 같은 내부 요인이 있다. 신제품 개발과정 요인의 경우 개발이전의 계획화, 학습, 커뮤니케이션, 상위(최고)경영층의 몰입과 신제품 출시에 따른 전략과 마케팅 노력의 정도를 의미하며 게품의 경쟁우위 요인의 경우 신제품 가격과 품질의 우위성과 시장 진입의 적시성(time to market)을 포함한다.

신제품 개발 과정은 개발에 필요한 시장지식과 기술지식올 흡수, 활용하는 일종의 학습(learning)과정이며 신제품 개발에 있어서 팀의 역량은 고객과 경쟁자에 대한 지식 창출과 이러한 지식을 기술과 결합하는 것이다. (Drucker, 1985). 기업은 신제품 개발과정에서 필요한 많은 지식(정보)을 획득하여 기존의 지식과 결합합으로써 새로운 지식을 창출하고 이를 제품으로 구체화하는 것이다. 이러한 신제품 개발 과정에서는 개별적인 개인이 
효율적으로는 보유하기 힘든 집합적인(collective) 지식이 요구된다는 측면에서 다기능적인 신제품 개발 팀의 학습과정의 효율성이 신제품의 성과에 직접적인 영향을 미친다고 볼 수 있다. 즉, 필요한 집합적인 지식을 얼마나 잘 활용하는가에 따라 신제품의 경쟁우위 요소가 발생하는 것이다. 그러므로 신제품 개발과정에서의 학습활동(조직 학습)이 신제품경쟁우위률 발생시키는 중요한 요인인 것이다.

신제품의 성공 요인으로 제시되는 다양한 요인들 중 많은 연구자들이 신제품의 품질, 즉 제품의 우수성이 가장 중요한 요인임을 지적하며 신제품 품질 수준을 높이기 위한 효과적인 방법으로 다기능적 제품 개발텀(cross-functional product development team)의 중요성을 강조하고 있다(Clark and Fujimoto 1991; Garvin 1988). 즉, 신제품 개발과정에서는 개별적인 개인이 보유하기 힘든 많은 지식과 정보가 필요하기 때문에 마케팅, 연구개발 (R\&D), 생산 부서와 같은 다양한 영역에서의 협력을 필요로 한다. 그러나 다기능적 제품 개발팀의 유용성과 중요성을 제시한 연구는 많으나 실제로 이러한 다기능적인 팀이 어떻게 신제품 경쟁우위에 영향을 미치는 가에 대한 연구는 부족하다고 할 수 있다. 기업의 구조적인 혹은 문화적인 촉면에서의 연구(Clark and Fujimoto 1991; Menon, Jaworski, and Kohli 1997; Morgan and Piercy 1998; Song, Souder, and Dyer 1997) 가 있었으나 신제품 개발 팀 수준에서의 팀 역량과 신제품 우위 요인과의 관계를 설명하기에는 부족하다.

신제품개발에 관한 최근의 연구에서는 신제품개발과정을 학습과정으로 인식하여 학습과정의 효율적인 측면을 부각하고 있는 연구가 있다(eg; Adams, Day, \& Dougherty, 1998; Ottum \& Moore, 1997; Moorman \& Miner, 1997; Song, Souder, \& Dyer, 1997; Madhavan \& Grover, 1998; Li Tiger \& Calantone, 1998). 그러나 Song, et al.(1997)의 연구 이외에는 시장지식의 측면에 한정하여 마케팅정보처리(marketing information processing)과정을 학습과정과 동일시하는 한계를 가지고 있으며 Song, et al.(1997)의 경우도 과정으로서의 지식활용의 측면보다는 지식의 보유에 초점을 맞추고 있는 한계를 가지고 있다. 따라서 본 연구는 신제품 개발 팀을 하나의 학습 조직(learning organization)으로 파악하고 개발 팀의 학습 능력과 학습 능력을 지원할 수 있는 팀의 구조/분위기적인 특성이 신제품 경쟁우위의 달성에 중요한 요인임을 제시하고자 한다.

\section{2. 이론적 배경과 가설의 설정}

\section{1 신제품 개발 성과}

모든 기업의 신제품 개발 목적은 시장에서의 성공이며 이는 신제품이 기존 제품이나 경쟁제품에 비하여 경쟁 우위를 가져야 가능하다. 그러므로 신제품 개발과정에서의 성과는 신제품이 시장에서 성공할 수 있는 경쟁우위를 얼마나 가지는가에 달려 있다. Brown \& Eisenhardt (1995)은 25년간의 조직 지향적인 신제품 개발 연구에서의 결과로 신제품 개발의 효율적인 과정, 효과적인 제품 그리고 풍부한 시장이 신제품의 재무적인 성과에 영향을 미친다고 하였다. 풍부한 시장요인은 외부 환경요인으로 개별기업의 입장에서 통제 가능성의 정도가 낮기 때문에 신제품 개발 기업의 입장에서는 “효과적인 제품 개발" 을 
“효율적" 으로 달성함으로써 재무적인 성과를 달성할 수 있다. 효과적인 개발이라 함은 제품 측면에서의 경쟁우위를 달성하는 것이며 효율적인 개발이라 함은 비용과 시간 측면에서 투입 대비 산출의 효율성을 달성하는 것이다. 즉, 경쟁 제품에 비하여 고객에게 더 많은 가치를 제공할 수 있어야 하는 것이다. 최근 제품수명주기가 짧아지고 있는 마케팅 환경에서 신제품 시장화의 속도가 중요한 경쟁우위 요인이 된다. 제품 수명주기가 짧아 기회의 창이 좁아지게 되는 상황에서 신속한 신제품의 개발이 요구되는 것이다(Eisenhardt, 1989; Stalk \& Hout, 1990).

제품 특성으로서의 신제품의 품질 수준은 성공과 밀접한 관계가 있다(eg; Maidique \& Zirger, 1984; Cooper \& Kleinschmidt, 1987; Song \& Parry, 1996). 그러므로 신제품이 얼마나 우수한 품질의 제품이냐의 문제가 신제품 개발과정의 성과로 인식되어야 할 것이다. 성공하는ㄴ 신제품의 특성의 경우 기존 연구자들 간 차이는 있으나 신제품의 품질, 신뢰성, 새로움(newness), 독특성(uniqueness) 둥을 공통적으로 지적하고 있다.(eg; Day \& Wensley, 1988; Zirger \& Maidique, 1990; Cooper \& Kleinschmidt, 1987; Song \& Parry, 1996).

신제품의 품질은 소비자의 제품에 대한 신뢰와 적합성(compatibility)에서 비롯되며 궁극적으로 소비자 만족으로 측정되는 것으로 본다(Zirger \& Maidique, 1990), 제품의 독특성은 형태의 독특성과 과업 수행의 독특성으로 구분되어 측정되어지는데 이러한 독특성의 의미는 차별성의 의미와도 통한다. 신제품이 겅쟁제품과 비교하여 가지는 독특성 (uniqueness)은 기존제품이나 경쟁제품에 대한 차별적 톡성을 가져오는 요소이다. 기존의 연구들을 통하여 본 연구에서는 제품 독톡성, 경쟁제품과의 차별성, 그리고 품질 우수성(신뢰성)을 제품특성우위를 구성하는 변수로 측정하고자 한다.

신제품 개발의 속도가 기업의 경쟁우위를 향상시킨다(Cooper \& Kleinschmidt, 1994). 톡히 하이테크(hi-tech) 제품의 경우 시장의 진입순서가 시장에서의 성과에 상당한 영향을 준다. 신제품의 개발에 걸리는 시간(time) 오래될수록 많은 환경적인 요인올 고려한 신중한 전략올 추진할 수 있는 장점이 있올 지라도 신제품에 개발에 필요한 자원의 소비가 많을 것이다(Stalk \& Hout, 1990; Clark \& Fujimoto, 1991). 그러므로 신속한 제품 개발이 몇 가지의 함정이 있을 지라도 성공적인 적응과 궁극적인 기업의 생존에 있어 중요한 요소가 된다(Eisenhardt \& Tabrizi, 1995).

경쟁우위 요소로서 시간 효율성의 측정의 경우 기존 연구에서는 개발 초기에서 신제품을 출시하기까지, 시장화에 걸리는 순환주기(cycle time)를 신제품 개발속도의 개념으로 파악하고 있다(eg; Mansfield, 1988). 신제품 개발 프로젝트의 실제 수행에 대한 판단과 개발 순환주기가 짧다고 효율적인가?에는 의문의 여지가 있다. 그러므로 본 연구에서는 개발 속도의 효율성을 '신제품 개발 프로겍트의 적시성(timeliness)' 과 '시간 효율성(time efficiency)' 의 의미로 파악하고자 한다(Cooper \& Kleinschmidt, 1994). 적시성의 의미는 프로젝트의 예정된 시간(schedule)과의 일치성의 여부(Mcdonough \& Barczak, 1991)로서 측정하고 시간 효율성은 프로젝트가 얼마나 시간 효율적으로 이루어졌는가? 예상되는 가장 최소한의 신체품 개발 프로젝트 속도와 수행된 프로젝트와의 상대적인 비교 수준으로 측정되어진다(Cooper \& Kleinschmidt, 1994).

이에 따라 본 연구에서는 신제품이 성공하기 위한 경쟁우위 확보를 신제품 개발의 성과로 파악하여 신제품 품질 우수성과 개발에 따른 시간 효율성을 신제품 개발과정의 성과로 인식하고 개발과정에서의 성과는 시장에서의 신제품 성공으로 이어질 것이다. 
H1: 신제품 개발과정에서 달성한 제품 특성우위가 높울수록 신제품 성공 가능성이 높다 $\mathrm{H} 2$ : 신제품 개발과정에서 시간 효율성이 높을수록 신제품 성공 가능성이 높다

\section{2 신제품 개발팀 특성과 신제품 개발 성과}

신제품 개발의 성과에 영향을 미치는 신제품 개발팀의 요인은 다양하다. 기존의 연구에서 신제품 성과를 가져오는 하나의 요인으로 다기능 개발팀의 중요성올 강조하고 있으나 개발 팀의 구체적인 특성들이 어떻게 신제품 개발성과를 가져오는가에 대한 텀 관련 요인들과 신제품 개발 성과와의 관계에 대한 설명으로는 부족하다. 신제품 개발 과점올 합리적인 계획과 내/외부 지식의 효율적인 커뮤니케이션을 통한 문제해결과정으로 이해하고 문제 해결의 결과가 새로운 신제품으로 구체화 되는 것이다. 그러므로 주어진 문제를 어떻게 해결하는가의 과정을 하나의 학습과정으로 이해할 수 있다.

조직은 조정된 활동을 수행하는 개인들의 집합으로서(Duncan \& Weiss, 1978) 목적 지향적인 활동 시스템이다. 그리고 이러한 조직 시스템의 효과성은 중요한 전략적 선택을 하는데 있어 이용가능한 지식기반의 품질에 의하여 결정된다고 할 수 있다(Shrivastava, 1983). 조직의 지식 기반은 개인들의 결합된 지식과 결합의 과정 즉, 학습을 톻하여 새롭게 창출되는데 이러한 새로운 지식이나 통찰력의 개발이 조직학습이다(Sinkula, 1994). 조직 차원에서의 학습은 동태적인 과정으로서 과거의 학습된 결과가 조직 기억으로 저장되며 이러한 조직 기억은 다음의 유사한 문제의 해결과정에 이용된다.

고객/시장과 관련한 정보와 기술을 결합하여 제품으로 구체화하는 과정으로서의 학습 결과물이 신제품이며 신제품의 경쟁우위를 확보하는 것이 개발의 성과라고 볼 때 학습 과정을 원활하게 수행하는 (1) 신제품 개발 팀의 학습 관련 행동 및 이러한 학습 과정을 효율적으로 지원하는 (2) 신제품 개발팀의 구조나 분위기가 신제품 개발 성과를 가져오는 중요한 결정 변수가 될 것이다.

다기능적인 팁으로서의 신제품 개발 팀에서의 학습은 기능적인 영역간 단순히 결합된 작업을 수행하는 것만을 의미하는 것이 아니라 정보통합(information integration)으로 해석되어야 하는데 이것은 특정한 과정에서의 상호 작용올 의미한다. (Sethi, 2000). 그러므로 신속하고 실수가 없도록 신제품을 개발하기 위하여 기업의 모든 기능들의 상호작용(interface)이 중요하다. (Gupta, Raj, \& Wilemon, 1986, p.7) 효과적인 상호작용은 다기능적인(cross functional) 활동과 토론 그리고 정보 교환을 홍하여 이루어지며(Cooper \& Kleinschmidt, 1991.p.140) 이 과정에서 기업의 신제품 개발과 관련한 사전 경험에 따라 효율적이고 효과적인 개발의 가능성이 달라지게 된다. 이러한 사전 경험은 조직 학습 이론에서 중요하게 다루어 지는 조직 기억(organizational memory)으로서 축적된 지식 양, 확산정도, 접근(검색)의 가능성은 신제품 개발의 성과에 많은 영향을 준다. 조직기억의 작용은 정보에 대한 체계적인 분석 기준을 제시하고 의미있는 정보를 걸러내는 역할을 수행할 수 있는 것이다. 다기능적 텀 내에서의 상호 작용은 구성원 간 갈둥올 발생 시키고 이 과정예서 갈등 해소를 위한 구조와 집단 규범이 개발되기도 한다(Slater \& Narver, 1995).

즉, 신제품 개발 텁은 정보 공유(통합)를 위한 커뮤니케이션(communication)과 정보 공유를 원활하게 하는 분위기, 텀 활동을 통제/관리하는 비공식적, 공식적 구조와 같은 특성을 포함하는 학습시스템의 형태로 제도화된다(Shrivastava, 1983). 


\section{2 .1 신제품 개발팀의 조직 학습}

개발할 신제품에 대한 공통된 이해와 신제품 개발과정에서 의사결정의 일치가 이루어 지는 것이 우수한 품질의 제품을 개발하는 데 매우 중요하다(Clark \& Fujimoto, 1991; Garvin, 1988; Monon et al., 1997). 다양한 기능 영역에서 역할을 수행하던 개인들은 제품에 대한 다른 아이디어를 가지고 있기 때문에(Garvin, 1988; Dougherty,1992) 효과적인 정보공유(통합)가 이루어지지 않는다면 신세품 개발과정에서 우수한 품질의 신제품을 개발하기 힘들 것이다. 앞서 언급한 바와 같이 다기능적인 팁은 상호 작용을 통한 정보 공유를 수행하여야 하고 이 과정에서 시장/고객에 대한 정보와 기술의 결합이 요구된다. 고객의 선호나 오구에 대한 시의 적절한 정보와 이를 이해하는 시장 지향성이 신제품의 성공에서 중요한 요인으로 지적되고 있으며(Cooper, 1993; Maidique \& Zirger, 1984; Adams et al., 1998) 기술의 빠른 변화와 확장, 기술적 상호 관계성의 중가와 같은 현상은 신제품 개발과정에서 마케팅과 기술관련 부서(R\&D/엔지니어링)의 상호 작용의 중요성을 중가시킨다. 다양한 지식이 결합될 때 고객의 욕구를 충족할 수 있는 우수한 방법올 개발할 수 있을 것이다. 예를 들어 R\&D는 제품 성능을 향상시킬 수 있는 아이디어와 제품의 신뢰성을 높이기 위한 아이디어를 마케팅과 엔지니어링으로부터 얻을 수 있다.(Clark \& Fujimoto, 1991; Monon et al., 1997) 기존의 신제품 성과에 대한 연구에서도 기능간의 팁 구축을 통한 시너지(synergy; Souder,1988; Song \& Parry,1996), 내부 커뮤니케이션을 통한 학습(Imai et al.,1985; Takeuchi \& Nonaka,1986) 또는 정보의 공유와 확산(Myers \& Marquis, 1969; Ancona \& Caldwell, 1992)이 신제품 성과에 중요한 요인이 되고 있음을 지적하고 있다.

H3: 신제품 개발 팀 내에서 정보공유 정도가 높올수록 더 높은 신제품 특성우위(신제품 품질 성과)를 달성할 것이다.

정보 공유를 통한 상호 작용과 더불어 이전의 문제 해결과정에서 발생한 능력이나 지식이 얼마나 잘 축적되어 있는가? 그리고 이러한 축적된 지식에 대한 접근성이 얼마나 용이한가와 같은 조직 기억이 신제품 개발 팀 내에서 학습과정이 효과적으로 이루어지기 위해 매우 중요한 의미를 지닌다. 특정한 현상에 대하여 저장하고 있는 정보의 양 (amount)과 확산정도 및 조직 기억에 대한 접근가능성(검색 능력:Day, 1994; Garud \& Nayyar, 1994; Walsh \& Ungson, 1991)에서 조직간 차이가 존재하며 이러한 차이는 조직 학습의 정도에 차이를 가져 온다.(Dickson \& Sinkula, 1994) 조직 기억이 집단적 사고(group thinking)를 유도하고 기존의 행동 패턴을 고수하려는 경향을 자극하여 조직의 혁신을 억제한다는 주장이 제시하는 연구들이 있으나(Ghemawat, 1991; McDonough, 1993) 일단 신제품 개발을 위한 신제품개발 팀이 구성되는 것과 같이 변화/혁신의 행동올 조직이 취하게 되는 경우라면 조직기억의 축적수준/학산정도, 접근가능성이 높을수록 학습하는 능력이 우월할 가능성이 높다. (Cohen \& Levinthal, 1990; Mooreman \& Miner, 1997).

조직 기억의 활용도가 높다는 의미는 신제품 개발과정에서 필요한 사전 지식이나 정보량이 많고 그에 대한 접근성이 용이하다는 의미로서 신제품 개발과정에서 탐색된 시장 정보와 기술에 대한 가치 평가/처리의 효율성올 가져올 수 있다. 새로운 정보률 이해할 수 있는 능력은 기존 지식올 범주화하고 이들간의 관계를 형성할 수 있는 능럭과 관련이 있다(Bower \& Hilgard, 1981). 신제품 개발과 관련한 기존의 연구에서도 기술 숙련도와 
마케팅 숙련도가 신제품 성과에 영향을 미침을 지적하고 있는데(Cooper \& Kleinschmidt, 1994; Song \& Parry, 1996) 이러한 숙련도는 과거 경헙에 의한 학습 과정 혹은 결과물을 시간적인 차원에 따라 이전함으로써 가능한 것이다.

이전 단계에서의 흡수능력의 축적은 다음 단계에서의 지식의 축적을 더욱 흐과적으로 할 수 있게 하며 문제 해결을 위한 아이디어나 기법(techniques)이 축적된 과거의 기억으로부터 전환된 된 것이다. 조직 기역은 고객의 욕구나 기술등과 관련하여 신제품 개발에 필요한 많은 정보를 제공할 수 있고 이러한 정보는 신제품의 품질 수준을 높일 수 있다.

$\mathrm{H} 4$ : 조직 기억의 활용도가 높을수록 신제품 특성우위가 높아질 것이다.

신제품 개발 팀이 조직 기억올 활용함으로써 문제 해결 과정을 효율적으로 수행하여 신제품개발과정에 투입되는 시간을 단축시킬 수 있다. 언급된 바와 같이 조직 기억은 필요 정보와 불필요한 정보에 대한 판단을 하기 위한 휴리스틱(heuristic)적인 탐색과정(Nelson, 1984)올 효율적으로 수행할 수 있고 필요한 정보를 신속하게 흡수할 수 있는 흡수능력(Cohen \& Levinthal, 1990)이 확장하여 신제품 개발과정을 효율화할 수 있다.

H5: 조직 기억의 활용도가 높을수록 신제품 개발과정에서의 시간효율성이 높아질 것이다.

\section{2 .2 신제품 개발팀의 분위기}

신제품 개발팀의 구조/분위기 특성이 신제품 개발 성과에 영향을 미친다. 팀은 분리된 개인들로 구성되어 있고 각 개인은 특정한 기능을 담당하고 있다. (Bereiter \& Scardarnalia, 1993, p.118) 학습 조직으로서의 신제품 개발 팀을 이해할 때 개별적이고 분산된 팀 구성원의 지식이 호과적으로 조정된 집단으로 이해되어야 한다. 이러한 관점에서 보면 팀의 성과는 개인들이 수행하는 기능 뿐만 아니라 분리되어 있는 개별적인 인지활동이 어떻게 조정되는가도 팀의 성과에 중요한 역할을 한다. 즉, 신제품 개발팀의 성과는 팀 구성원들간의 지식 상호작용으로서의 학습과정과 팁 구성원들의 상호 작용의 상황이 팀 내에서 어떻게 조성되는가에 영향올 받는 것이다.

본 연구에서는 신제품 개발팀의 신뢰(trust) 요소와 자율적 분위기에 대한 영향변수를 고려하고자 한다. 신제품 개발 성과에 영향울 미치는 정보공유는 커뮤니케이션 과정을 통하여 이루어지고 커뮤니케이션과 관련된 연구에서는 커뮤니케이션에 영향을 미치는 요소로서 유기적인 구조나 몰입/신뢰의 분위기에 대한 요인울 제시하고 있다(Anderson \& Narus, 1990; Morgan \& Hunt, 1994; Kohli \& Jaworski, 1990).

마케팅과 R\&D 혹은 엔지니어링과 같은 다기능의 상호의존성이 필요한 경우 상호 호혜성이나 신뢰는 매우 중요한 역할을 한다. Nonaka(1994)의 경우 새로운 지식의 창출과정에서 구성원들간의 상호신뢰를 형성할 필요성올 강조하였는데 이는 지식 창출 과정예서 필요한 계속적인 대화나 반영(reflection)의 활동은 반복적이고 시간 소비적이기 때문에 이러한 활동의 기반이 되는 상호신뢰(Schrage, 1990)는 정보 공유를 통한 지식 구체화 작업(예를 들어신제품 개발)을 용이하게 한다(Nonaka, 1994). 신뢰의 부족은 지식형성과 내부화, 반영(reflection)의 과정에 부정적인 영향을 미치게 되며(Hedlund \& Nonaka, 1993) 신제품 개발과정에서의 높은 신뢰수준은 정보 공유와 창조적인 아이디어에 대한 위험을 감수하게 하여 공동 창조적인(co-creative)작업올 효과적이고 효율적으로 
수행할 수 있도록 한다.(Jassawalla \& Sashittal, 1998) 신뢰가 부족한 상황에서는 정보를 유보하여 커뮤니케이션에 의한 정보 공유가 제한되거나 조직의 자원을 좁은 이해관계나 팀의 목적과는 다르게 분산시킬 위헙성이 존재한다. (Zand, 1981)

H6: 신제품 개발 팁 내의 구성원간 신퇴수준이 높을수록 정보 공유가 원활하게 될 것이다.

기업 입장에서는 보면 일종의 창조된 불확실성이지만 신제품을 개발하는 과정은 개발. 이전 보다는 더 많은 불확실성에 직면하게 되는 것이고 개발팀의 경우 이러한 불확실성올 제거하려는 노력을 한다. 이러한 불확실성의 제거는 정보처리과정을 통하여 이루어지게 된다. (Moenaert \& Souder, 1990) 불확실성이 높은 상황에서 상대방의 커뮤니케이션의 품질에 대한 평가가 어려워 지면 불학실성을 제거하기 위한 정보처리 과정이 중첩되고 불필요한 갈둥이 유발될 수 있다. 도한 이질적인 지식 베이스를 기반으로 하는 마케팅이나 R\&D부서의 경우 상호 능력에 대한 신빙성의 부족과 이로 인한 상호 불인정이 팀 내 갈둥의 원인이 될 수 있다. 이러한 갈둥은 상호간의 신뢰룰 통하여 해졀될 수 있으며(Dore, 1983; Zucker, 1986) 신뢰는 신제품 개발과정에서 기능간의 협력을 순조롭게 한다. (Souder, 1988; Song \& Parry, 1996) 그리고 구성원간의 갈등을 해졀하기 위한 불필요한 조직 활동올 제거함으로써 의사결정과정을 신속하게 할 수 있을 것이다.

H7: 신제품 개발 팀 내의 구성원간 신뢰수준이 높을수록 신제품 개발과정에서의 시간 효율성이 높을 것이다.

자율성(autonomy)은 신제품 개발과정에서의 구성원 개인의 권한과 업무의 독립성을 의미한다. 이러한 측면에서 신제품 개발 팀 내에서 자율성올 보장한다는 것은 분권화와 탄력성의 개념올 포함하고 있는 것이다. 구성원 개인들이 정보를 공유하는 과정에서 정보 획득, 인과관계 설정, 해석에 어느 정도의 탄력성을 가짐으로쌔 새로운 지식 창출이 효과적으로 수행되고(Nonaka, 1994) 중요한 것들만 최소한으로 명시되어 자율성이 보장되는 시스템은 자기화 조직(self-organization)의 기초를 형성하게 되며 이매 개인의 자율성이 지식 창출에 대한 동기가 형성될 가능성이 높다.(Morgan, 1986) 학습 조직에 대한 연구에서도 효과적인 정보공유는ㄴ 정보흐름에 대한 구조적인 제한이 해체되어야 한다고 주장하고 있다. (Mintzberg, 1987; Woodman, Sawyer, \& Griffin, 1993)

H8: 신제품 개발 팀 내에서 자율성의 수준이 높을 수록 정보 공유가 원활하게 될 것이다.

높은 수준의 자율성은 분권화나 공식성의 수준이 낮다는 의미와 관계가 높다. 업무의 독립성을 보장하기 위해서는 조직의 목적성에 적합한 최소한의 것들에 대해서만 절차와 규칙을 수립하고 권한의 분산을 통한 분권화가 이루어져야 한다. 즉, 유기적인 구조가 구성원의 자율성을 높여줄 수 있다. 분권화, 낮은 공식성의 수준, 구성원의 자율성을 포괄하는 개념으로서 유기적인 조직은 기계적인 조직과 대비되는 것으로 환경에 대한 적웅력이 높은 것으로 인식되고 있다. (Hedberg, Nystrom, \& Starbuck, 1976) 그러므로 외부환경에 대한 높은 적옹성은 신제품 개발과정에서 필요한 신속한 의사결정이 가능하고 신제품 개발과정의 시간 효율성을 높일 것이다. 
H9: 신제품 개발 팀 내의 구성원들의 자율성이 높을수복 신제품 개발과정에서의 시간 효율성이 높을 것이다.

\section{그림 1 연구}

모형

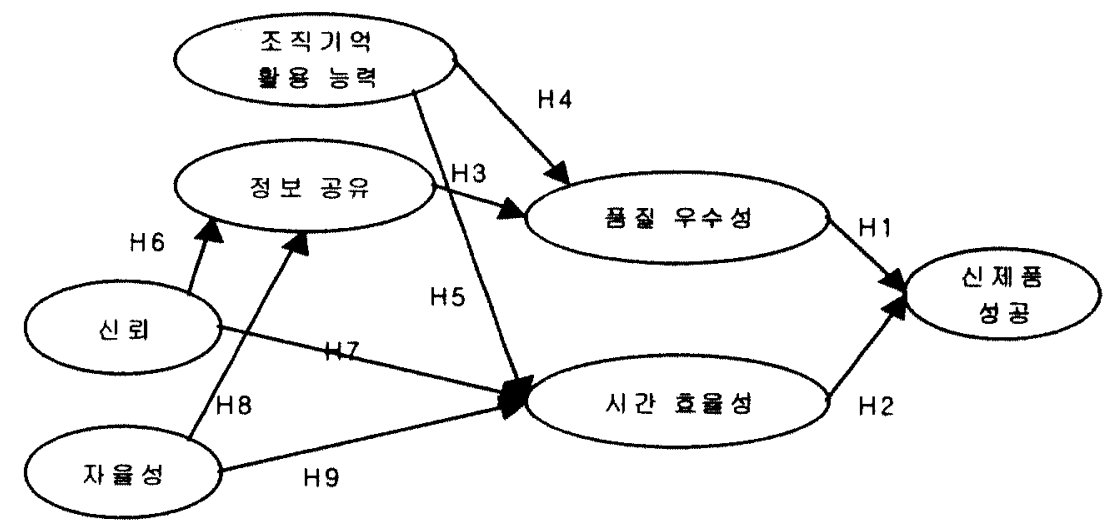

\section{3. 실중 분석}

\section{1 조사 방법}

본 연구는 가설에서 제시된 바와 같이 신제품 개발 팁의 특성과 신제품 개발팁의 특성에 대한 인과적인 관계에 대한 분석올 하였다. 최근 3 년 이내에 신제품이 개발되고 개발된 신제품의 경우 출시된 지 6개월이 지난 신제품을 대상으로 하였다. 신제품이 개발된 지 3 년 이상인 경우 개발 상황에 대한 기억의 오류가 있을 것으로 예상하였으며 출시 6개월이 지나지 않은 제품의 경우 시장에서의 성공여부에 대한 평가가 이루어지지 않았을 가능성 때문이었다. 표본은 상공회의소의 홈페이지(http://www.kcci.or.kr/)에 있는 기업체 총람을 표본 프레임으로 하여 530 개의 업체를 무작위로 추출하였다. 조사의 결과 촣 133 개의 표본이 얻어졌으며 이 중 응답이 불성실한 2 개의 표본을 제외한 131 개의 표본이 실증분석에 이용되었다. 설문에 응답한 기업은 대기업이 42\%, 중.소기업이 $58 \%$ 를 차지하고 있으며 업종별로는 음. 식료업(10.7\%), 화학(18.3), 제약(26.0\%), 조립금속. 기계(17.6\%), 전자-소프트웨어(27.5\%)로 구성되어 있다. 제품 개발을 책임지고 있는 신제품 개발팀이 설문조사의 표본 단위이며 설문응답의 경우 핵심옹답자(key informant)에 의한 방법을 
이용하였다. (Phillips, 1981, p.396) 설문웅답에 웅한 웅답자의 직위는 차장급 이상이 $58.3 \%$ 이며 과장급 이하의 경우가 $41.7 \%$ 로 나타났다.

\section{2 분석 결과}

\section{2 .1 신뢰성 및 타당성 분석}

본 연구에서 사용된 변수들은 다항목으로 측정되었으며 SPSS 10.0을 이용하여 신뢰도 분석을 수행하고 요인 분석을 통하여 측정 개넘들의 타당성을 확인하였다. (표 1 참고) 신뢰성의 측정은 Cronbach $\alpha$ 로 측정하였으며 시간 효율성과 자율성 개념을 제외하고는 상당히 높은 내적 일관성울 보인다고 할 수 있다. 타당성의 경우 요인분석의 결과에서 보듯이 어느 정도 개념들간 변별 타당성이 확인되었다.

\section{표 1 구성 개념과 측정항목}

\begin{tabular}{|c|c|c|}
\hline 변수 & 측정 항목 & $\begin{array}{l}\text { 신뢰 } \\
\text { 계수 }\end{array}$ \\
\hline $\begin{array}{l}\text { 정보 공유 } \\
\text { (SHARE) }\end{array}$ & $\begin{array}{l}\text { 아이디어개발과 개념화에 기술부문의 지원이 있었다(SHARE1) } \\
\text { 팀 구성원간 상호 정보를 공유하였다(SHARE2) }\end{array}$ & 0.92 \\
\hline $\begin{array}{l}\text { 조직기억 활용 } \\
\text { (MEMORY) }\end{array}$ & $\begin{array}{l}\text { 개발에 필요한 사전 지식의 축적이 있었다(MEMORY1) } \\
\text { 축적된 DB에 대한 팁원돌의 접근이 용이하였다(MEMORY2) }\end{array}$ & 0.81 \\
\hline $\begin{array}{l}\text { 신뢰 } \\
\text { (TRUST) }\end{array}$ & $\begin{array}{l}\text { 팀원들의 능력과 역량에 대한 신뢰가 있었다(TRUST1) } \\
\text { 팁 구성원간 호혜적인 행동을 할 것이라는 신뢰가 있었다(TRUST2) }\end{array}$ & 0.66 \\
\hline $\begin{array}{l}\text { 자율성 } \\
\text { (AUTONONY) }\end{array}$ & $\begin{array}{l}\text { 의견올 제안하는 행동에 있어 개인의 자을성이 높았다(AUTOMY1) } \\
\text { 개발업무에 관하여 팁원들의 독립성이 보장되어 있었다(AUTOMY2) }\end{array}$ & 0.74 \\
\hline $\begin{array}{l}\text { 품질우수성 } \\
\text { (QUALTY) }\end{array}$ & $\begin{array}{l}\text { (경쟁제품대비) 고객에게 독특한 혜택을 재공한다(QUALITY1) } \\
\text { 해당 신제품은 차별성이 높은 제품이다(QUALITY2) } \\
\text { 해당 신제품의 품질의 신뢰성이 높다(QUALITY3) }\end{array}$ & 0.87 \\
\hline $\begin{array}{l}\text { 시간 효율성 } \\
\text { (TIMEFF) }\end{array}$ & $\begin{array}{l}\text { 개발 과업 수행에서 시간을 효울적으로 사용하였다(TIMEFF1) } \\
\text { 신제품 개발 시간은 이상적(ideal)으로 걸린 시간이었다(TIMEFF2) } \\
\text { (경쟁제품 대비) 신제품의 시장화 시간이 적었다(TIMEFF3) }\end{array}$ & 0.88 \\
\hline $\begin{array}{l}\text { 신제품 성공 } \\
\text { (PERFORM) }\end{array}$ & $\begin{array}{l}\text { 예상 판매량과 비교할 매 해당 신제품은 매우 성공적이다 (PERFORM1) } \\
\text { 예상 시장 점유율과 비교할 때 매우 성공적이다(PERFORM2) } \\
\text { 예상 수익성과 비교하여 볼 때 매우 성공적이다(PERFORM3) }\end{array}$ & 0.63 \\
\hline
\end{tabular}

신제품 경쟁 우위의 영향 요인인 정보 공유, 조직기억의 활용, 신뢰, 자울성이 다른 구성 개념으로 구분되었으며 신제품 경쟁우위와 신제품 성공 개넘 또한 서로 다른 개념으로 구분되었다. (표 2 참고) 
표 2 측정 항목에 대한 요인 분석 결과

\begin{tabular}{|c|c|c|c|c|c|c|c|}
\hline & \multicolumn{7}{|c|}{ 성분 } \\
\hline & 1 & 2 & 3 & 4 & 5 & 6 & 7 \\
\hline MEMORY 1 & (7) & 0.1506 & 0.1647 & 0.1209 & 0.1362 & 0.0289 & 0.1575 \\
\hline MEMORY2 & 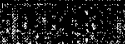 & 0.1137 & 0.2719 & 0.0682 & 0.0470 & 0.1129 & 0.2183 \\
\hline TRUST1 & 0.1261 & Wher & 0.2301 & 0.1549 & 0.1426 & 0.0796 & 0.1755 \\
\hline TRUST2 & 0.2055 & (1) & 0.1646 & 0.2016 & 0.0955 & 0.1202 & 0.1945 \\
\hline SHARE2 & 0.3522 & 0.2495 & I & -0.0314 & 0.2614 & -0.0235 & 0.0318 \\
\hline SHARE1 & 0.2504 & 0.1944 & & 0.3670 & 0.1544 & 0.0399 & 0.2639 \\
\hline AUTOMY 1 & 0.0609 & 0.2843 & 0.2526 & & -0.0156 & 0.0725 & 0.0553 \\
\hline AUTOMY2 & 0.5281 & 0.1290 & -0.0974 & & 0.2533 & 0.1238 & -0.0370 \\
\hline QUALTY2 & 0.0265 & 0.0884 & 0.1626 & 0.0746 & & 0.0283 & 0.2263 \\
\hline QUALTY3 & 0.1659 & 0.0797 & 0.0722 & -0.0027 & & 0.1377 & 0.2404 \\
\hline QUALTY1 & 0.4414 & 0.1974 & 0.0596 & 0.1453 & 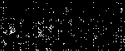 & 0.0797 & 0.4051 \\
\hline TIMEFF2 & 0.0323 & 0.2460 & 0.5817 & 0.2087 & 0.0026 & & 0.2100 \\
\hline TIMEFF 1 & 0.0812 & 0.1623 & -0.0296 & -0.0246 & 0.1634 & & 0.0955 \\
\hline TIMEFF3 & 0.1038 & -0.0727 & 0.3698 & 0.3943 & -0.0057 & 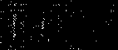 & 0.1957 \\
\hline PERFORM2 & 0.1037 & 0.0827 & 0.0884 & 0.0935 & 0.2441 & 0.1620 & \\
\hline PERFORY1 & 0.1246 & 0.1537 & 0.1070 & 0.0827 & 0.1657 & 0.1415 & \\
\hline PERFORM3 & 0.1800 & 0.1595 & 0.1345 & -0.0643 & 0.2088 & 0.0027 & 101. \\
\hline Eigenvalue & 2.25 & 1.86 & 1.71 & 1.54 & 2.04 & 1.47 & 2.84 \\
\hline$\%$ & 13.23 & 10.94 & 10.05 & 9.06 & 11.98 & 8.64 & 16.68 \\
\hline
\end{tabular}

\section{2 .2 가설 검증}

본 연구에서 제시된 가설을 검중하기 위하여 1 차적으로 희귀모형에 의한 가설 검중을 시도하였다. [그림 1]의 연구 모형에서 보듯이 품질 우수성(QUALTY)과 시간 효율성 (TIMEFF)은 신제품 성공(PERFORM)에 정(t)의 영향을 미치며 품질 우수성은 조직기억활용능력 (MEMORY)과 정보공유(SHARE), 시간 효율성은 조직기억활용능력과 신뢰(TRUST), 자율성 (AUTOMY)의 함수관계로 설정된다. 그리고 마지막으로 정보 공유는 신뢰와 자율성에 정(t)의 영향을 받는다. 이에 따라 본 연구에서는 가설에 따라 4 개의 회귀모형을 분석하여 가설울 점증하였다. ${ }^{1}$ 회귀분석에서는 다항목으로 측정된 변수의 평균값올 이용하였다.

\footnotetext{
${ }^{1}$ PERFORM $=\alpha_{1}+\beta_{11} \cdot$ QUALTY $+\beta_{21} \cdot$ TIMEFF (1)

QUALTY $=\alpha_{2}+\beta_{12} \cdot$ SHARE $+\beta_{22} \cdot$ MEMORY $+\beta_{32} \cdot$ TRUST $+\beta_{42} \cdot$ AUTOMY (2)

TIMEFF $=\alpha_{3}+\beta_{13} \cdot$ SHARE $+\beta_{23} \cdot$ MENORY $+\beta_{33} \cdot$ TRUST $+\beta_{43} \cdot$ AUTONY (3)

SHARE $=\alpha_{4}+\beta_{14} \cdot$ TRUST $+\beta_{24} \cdot$ AUTOMY (4)
}

PERFORM $=\alpha_{5}+\beta_{15} \cdot$ QUALTY $+\beta_{25} \cdot$ TIMEFF $+\beta_{35} \cdot$ SHARE $+\beta_{45} \cdot$ MEMORY $+\beta_{55} \cdot$ TRUST $+\beta_{65} \cdot$ AUTOMY(5) 
표 3 변수의 평균, 표준편차, 상관관계

\begin{tabular}{lcccccccc}
\hline \multicolumn{1}{c}{ 변수 } & 평균 & 표준편차 & $(2)$ & $(3)$ & $(4)$ & $(5)$ & $(6)$ & $(7)$ \\
(1) 신제품 성공 & 4.72 & 1.45 & $.575 * *$ & $.393 * *$ & $.403 * *$ & $.390 * *$ & $.400 * *$ & $.209 * *$ \\
(2) 품질우수성 & 5.33 & 0.96 & & $.333 * *$ & $.445 * *$ & $.450 * *$ & $.403 * *$ & $.306 * *$ \\
(3) 시간 효율성 & 4.10 & 1.02 & & & $.421 * *$ & $.339 * *$ & $.411 * *$ & $.409 * *$ \\
(4) 정보 공유 & 5.13 & 1.24 & & & & $.523 * *$ & $.522 * *$ & $.467 * *$ \\
(5) 조직기억 활용 & 4.53 & 1.29 & & & & & $.421 * *$ & $.453 * *$ \\
(6) 신뢰 & 4.74 & 1.09 & & & & & & $.462 * *$ \\
(7) 자율성 & 4.54 & 1.12 & & & & & & \\
\hline
\end{tabular}

회귀 분석에 의한 결과는 아래의 [표 4]와 같다. 신제품 성공에 대한 완전 모형(full model, 회거 모형 5)의 결과에서 보는 바와 같이 신제품 성공에 영향을 미치는 변수는 품질 우수성 $\left(\beta_{15}=0.637(t=5.16)\right)$ 과 시간 효율성 $\left(\beta_{25}=0.268(t=2.34)\right)$ 이며 다른 변수의 경우 직접적으로 신제품 성공에 영향을 미치지 않고 있다. 그러므로 제시된 가설 $\mathrm{H} 1$ 과 $\mathrm{H} 2$ 는 지지되는 것으로 판단된다.

신제품 성공에 영향을 미치는 품질 우수성의 경우 정보공유 $\left(\beta_{12}=0.163(\mathrm{t}=2.18)\right)$ 와 조직 기억의 활용능력 $\left(\beta_{22}=0.194(\mathrm{t}=2.84)\right)$ 변수만 통계적으로 유의한 결과를 보이고 있어 가설 H3과 $\mathrm{H4}$ 또한 지지되고 있다. 시간 효율성의 경우 신뢰 $\left(\beta_{33}=0.176(\mathrm{t}=2.01)\right)$ 와 자율성 $\left(\beta_{43}=0.182(\mathrm{t}=2.19)\right)$ 요인의 경우 가설에서 설정된 바와 같이 $(\mathrm{H} 7, \mathrm{H} 9)$ 통계적으로 유의한 결과를 보이고 있으나 가설 $5(\mathrm{H} 5)$ 에서 설정된 조직기억의 활용능력 $\left(\beta_{23}=5.3 \mathrm{E}-\right.$ $02(\mathrm{t}=0.72))$ 은 시간효율성에 유의한 영향을 미치지 않은 것으로 나타나고 있다. 이러한 결과는 오늘날 기술/시장 환경이 급격하게 변화하고 있어 기술/시장 지식의 진부화가 급속하게 진전되고 이에 따라 신제품 개발 과정에서 필요한 기술/시장 정보를 조직 기억에만 의존하기 어렵기 때문인 것으로 판단된다. 과거 지식을 잘 활용함으로써 신제품의 성능/기능을 향상시키기 지식 베이스로 활용하는 것은 의미가 있으나 급격하게 변화하는 환경에 따른 새로운 정보/지식의 필요성이 많이 요구되기 때문에 경헙/학습 효과에 의한 효율성은 과거에 비하여 둔화된다고 할 수 있다.

\section{표 4 회귀 분석에 의한 가설 검증}

\begin{tabular}{|c|c|c|c|c|c|}
\hline 종속변수 $(\mathrm{t}-$ 값 $)$ & 신제품성공(1) & 품질우수섬 (2) & 시간효율섬(3) & 정보공유(4) & 신제품성공 (5) \\
\hline 상수항 & $-0.641(-1.04)$ & $2.836(7.49)^{\circ}$ & $1.394(3.42)^{\circ}$ & $1.59(3.57)^{* *}$ & $-0.789(-1.23)$ \\
\hline 품질우수성 & $0.324(3.08)^{* *}$ & - & - & - & $0.637(5.16) *$ \\
\hline 시간 효율성 & $0.757(6.79) *$ & - & - & - & $0.268(2.34) *$ \\
\hline 정보공유 & - & $0.163(2.18)^{* *}$ & $0.158(1.96)^{\circ}$ & $\begin{array}{lll}- & - \\
\end{array}$ & $9.4 \mathrm{E}-02(0.87)$ \\
\hline 조직기억 활용 & - & $0.194(2.84)^{*}$ & $5.3 \mathrm{E}-02(0.72)$ & - & $0.116(1.19)$ \\
\hline 신뢰 & - & $0.158(1.95)^{\circ}$ & $0.176(2.01)^{* *}$ & $0.445(4.84)^{* *}$ & $0.179(1.55)$ \\
\hline 자율성 & - & $5.3 E-03(0.07)$ & $0.182(2.19)^{* *}$ & $0.317(3.55)^{\prime \prime}$ & $-0.184(-1.68)$ \\
\hline $\begin{array}{c}\text { 모델 적합도 } \\
\left(\mathrm{R}^{2} / \mathrm{F} \text { 값) }\right.\end{array}$ & $3.77 / 39.2^{* *}$ & $0.286 / 12.84^{* *}$ & $0.264 / 11.49^{*}$ & $0.337 / 33.1^{* *}$ & $0.411 / 14.67^{* *}$ \\
\hline
\end{tabular}


정보 공유의 정도에 영향올 미치는 변수로서의 신뢰 $\left(\beta_{14}=0.445(t=4.84)\right)$ 와 자율성 $\left(\beta_{24}\right.$ $=0.317(3.55)$ )의 영향에 대한 가설들의 경우 [표 4]에서 보는 바와 같이 통계적으로 유의한 결과를 보이고 있어 16 와 $\mathrm{H} 8$ 은 지지되는 것으로 나타난다.

본 연구에서는 회귀 분석의 결과를 바탕으로 연구 가설에 대한 정확한 검증을 위하여 연구 모형 1에 대한 공변량 구조 모형 분석을 수행하였다. 공변량구조분석의 경우 보다 현실적인 상황에서의 변수들간의 관계에 대한 분석을 가능하게 하고(이 순묵, 1990) 구조 방정식 모형에 의한 변수들간의 상호영향관계에 대한 통합적인 모형에 대한 검증을 가능하게 해줄 수 있다. 본 연구에서는 AMOS 4.0 을 이용하여 공변량구조 모형을 분석하였으며 그 결과는 아래의 [표 5]와 같다.

표 5 공변량 구조 분석에 의한 가설 검증

\begin{tabular}{|c|c|c|c|c|c|}
\hline & 대안 모형 & \multicolumn{4}{|c|}{ 연구모형 } \\
\hline 종속변수(C.R) & 신제품성 공 & 신제품성공 & 품질우수성 & 시간효율성 & 정보공유 \\
\hline 품질우수성 & $0.213(0.626)$ & $0.987(5.62)$ & - & - & - \\
\hline 시간 효울성 & $0.852(1.139)$ & $0.402(2.33)$ & - & - & - \\
\hline 정보공유 & $0.858(0.766)$ & - & $0.299(3.66)$ & - & - \\
\hline 조직기억 활용 & $0.141(2.156)$ & - & $0.273(3.79)$ & $0.091(1.31)$ & - \\
\hline 신뢰 & $0.415(1.395)$ & - & - & $0.291(3.29)$ & $0.521(4.94)$ \\
\hline 자율성 & $-1.182(-1.647)$ & - & - & $0.421(3.42)$ & $0.580(3.90)$ \\
\hline 모델 부합도 & $\begin{array}{l}x^{2}=228.6(p=0.00) / d \\
f=113, \\
G F]=0.602, \\
C F I=0.714, \\
T L I=0.656,\end{array}$ & $\begin{array}{l}\chi^{2}=26 \\
T L I=0.837\end{array}$ & $37(p=0.000) / d$ & 10, $\mathrm{GFI}=0.815$, & $\mathrm{CFI}=0.868$, \\
\hline
\end{tabular}

공변량 구조 분석의 경우 마이너스 오차분산과 같은 몇 가지의 예비적합도 분석과 더불어 전반적인 적합도 분석이 필요하다. 좋은 모델로 평가 되기 위한 일반적인 부합도 지수에 비추어 보면 공변량구조분석에 의한 본 연구의 연구모형의 부합도 지수는 다소 떨어지긴 하나 앞서 분석된 회귀모형의 결과와 비교,확인하는 차원에서 경로계수의 유의성을 통한 가설 검중을 시도하였다. [포 5]에서 나타난 바와 같이 신제품 경쟁우위 및 조직 학습 그리고 신제품 개발팀의 조직 분위기 변수들의 신제품 성공예 대한 영향관계에 대한 연구모형에서의 가설들이 대부분 지지되고 있다. 그러나 시간 효율성에 대한 조직 기억활용능력의 영향관계가 가설에서 설정된 것과는 달리 통계적으로 유의한 결과률 보이고 있지 않다. 그러므로 가설 5(H5)는 지지되지 않는 것으로 판단된다. 이러한 결과는 회귀분석을 통한 검증과 같은 결과이다. 회귀분석과 공변량구조분석에서 나타난 가설 검증의 최종적인 결과는 아래의 [표 6]에 나타난 바와 같다. 


\section{표 6 연구 모형 검중 결과}

\begin{tabular}{|c|l|c|c|}
\hline 가설 & \multicolumn{1}{|c|}{ 가설 내용 } & 희귀분석 & 공변량구조분석 \\
\hline 가설 1 & 품질 우수성 $\rightarrow$ 신제품 성공 & 지지 & 지지 \\
\hline 가설 2 & 시간 효율성 $\rightarrow$ 신제품 성공 & 지지 & 지지 \\
\hline 가설 3 & 정보 공유 $\rightarrow$ 품질 우수성 & 지지 & 지지 \\
\hline 가설 4 & 조직기억활용능력 $\rightarrow$ 품질 우수성 & 지지 & 지지 \\
\hline 가설 5 & 조직기억활용능력 $\rightarrow$ 시간 효율성 & 기각 & 기각 \\
\hline 가설 6 & 신뢰 $\rightarrow$ 정보 공유 & 지지 & 지지 \\
\hline 가설 7 & 신뢰 $\rightarrow$ 시간 효율성 & 지지 & 지지 \\
\hline 가설 8 & 자율성 $\rightarrow$ 정보 공유 & 지지 & 지지 \\
\hline 가설 9 & 자율성 $\rightarrow$ 시간 효율성 & 지지 & 지지 \\
\hline
\end{tabular}

\section{4. 결론 및 연구의 한계}

\section{1 결론 및 시사점}

본 연구는 조직 학습 이론을 기반으로 과거 연구에서 제시되는 다양한 성공 요인을 신제품 경쟁우위요인과 경쟁우위에 영향을 미치는 신제품 개발텀의 특성으로 구분하고 이들 간의 인과적 관계에 대한 실증 연구를 수행하였다. 3 장에서 제시된 실증 분석의 결과에서 보듯이 조직 학습 수행도와 이를 효과적으로 지원하는 조직 분위기가 신제품 경쟁우위롤 가져오며 신제품 경쟁우위률 확보하는 것이 신제품 성공으로 이러지는 것이다. 실증 결과에 기반한 본 연구의 시사점은 다음과 같다.

첫째, 신제품의 성퐁의 기반은 품질 우수성과 신제품 개발과정에서의 시간 효율성이다. 특히, 경쟁 강도가 심해지고 제품의 진부화가 매우 빠른 속도로 이루어지는 오늘날의 마케팅 환경에서는 신제품의 신뢰성과 차별성을 확보해야 함은 물론 신제품 개발과정에서 불필요한 시간 소비를 제거합으로써 신속하게 신제품 개발과정을 수행하는 것이 중요한 경쟁우위 요인이 된다.

둘째, 신제품 품질의 우수성은 기술 측면과 시장 측면에서 고려되어야 하는데 시장에서의 고객의 욕구에 부합되는 경쟁 제품과 차별화되는 제품이어야 하며 이러한 제품을 개발할 수 있는 기술적인 가능성이 수반되어야 한다. 이러한 이유에서 다기능적(cross-functional) 제품 개발팁의 중요성이 부각되는 것이다. 고립되어 있는 개인이 가지는 지식보다는 팁(team)이 가지는 지식이 더 많을 수 있지만 팀을 구성함으로써 얻어지는 정보의 시너지 효과는 개인들간의 정보 공유가 수행됨으로써 가능해지는 것이다. 개인의 지식 혹은 합리성이 제한되어 있으므로 신제품 개발 텀내 구성원간의 정보 공유(information sharing)는 시장에서 요구되는 바와 기술의 결합올 효과적으로 달성하는데 필수적이라 할 수 있다. 마케텅 부서와 $\mathrm{R} \& \mathrm{D}$ (생산,앤지니어링)부서가 서로 가지고 있는 정보.지식울 
공유하는 것은 신제품의 차별성/신뢰성을 확보에 있어 필수적인 활동이라 할 것이다.

셋째, 정보 공유롤 촉진하는 개발 팁의 분위기가 필요하다. 마케팅 부서는 시장의 요구에 민감한 반면 $\mathrm{R} \& \mathrm{D}$ (엔지니어링)부서의 경우 기술적인 가능성 민감하고 생산 부서는 생산의 효율성에 민감하다. 부서간의 지향성의 차이로 인한 갈등은 상호 신뢰를 떨어뜨리고 효과적인 정보 공유를 방해하는 요인이 된다. 그러므로 정보 공유를 원활하기 위한 조건은 상호간의 신뢰이다. 효과적인 정보 공유의 기반이 되는 신뢰는 다른 구성원의 능력에 대한 신뢰와 구성원의 의도.행위에 대한 호혜성 인식이라는 두 가지 측면에서의 신뢰가 요구된다. 신제품 개발 과정에 필요한 특정성이 높은 지식-정보를 가지고 있지 않은 다른 구성원의 경우 이러한 특정적인 지식을 완전히 이해하기 어렵다. 그러므로 특정적인 지식을 보유하고 있는 신제품 개발팁의 타 구성원의 능력에 대한 신빙성(credibility)을 인정하는 우호적인 분위기는 상호 신뢰에서 비롯된다 할 수 있다. 또한 구성원간의 신뢰는 불필요한 갈등을 사전에 제거함으로써 불밀요한 시간 소비를 줄인다.

넷째, 신제품 개발팁의 자율적인 분위기가 팀 내 구성원간의 정보 공유를 통한 품질 우수성 및 시간 효율성 달성에 중요한 요인이 된다. 개인의 자율성은 새로운 지식 창출의 동기 요인으로 작용하고 공식적인 절차와 규칙의 의존도를 낮추어 환경에 대한 신속한 적웅을 가능하게 한다. 유기적 조직 내의 구성원은 상호의존성을 인식과 협력 의지롤 가지고 있어 조직의 효과성을 유지하기 위하여 정보를 공유한다.(Miles \& Snow, 1992) 효과적인 정보공유는 정보흐름에 대한 체계적이고 구조적인 제한이 해체되어야 하며 정보.지식의 효과적인 확산을 위해서는 공식성을 낮추는 것이 필요하다. (Mint zberg, 1987)

다섯째, 신제품 개발의 과거 경험과 과거 경험으로부터 축적된 지식베이스(조직 기억)가 신제품 경쟁우위를 달성하는데 중요한 역할을 한다. 개발과정에 대한 경헙은 경험을 통하여 축적된 지식을 활용함으로써 신제품과 관련한 시장정보 및 기술올 효과적으로 결합함으로써 신제품 품질우수성을 달성할 수 있다. 혁신이나 조직 학습과 관련된 연구에서는 조직기억의 중요성을 강조하고 있다. 조직 기억은 새로운 지식과의 졀합을 용이하게 하는 수용능력 absorption capacity; Cohen \& Levinthal, 1990)으로 작용하기 때문에 필요한 신기술과 정보를 조직 내부로 흡수함에 있어 매우 중요한 역할을 한다. 기존 지식과 새로운 지식의 결합, 변한/재할성화를 통한 지식 재창출은 신제품의 품질 우수성을 달성할 뿐만 아니라 이러한 과정올 효과적으로 수행하는 능력이 조직 내에 암묵적인 지식으로 전환되어 타 기업의 모방을 억제하는 효과를 가져오게 되는 것이다. 핵심역량은 모방을 억제하는 할 수 있음으로써 지속적인 경쟁우위 창출의 조건이 되는 것이다.

\section{2 연구의 한계 및 향후 연구 방향}

몇 가지 전략적 시사점을 제공하는 연구의 결과에도 불구하고 실중연구를 진행하여 가설올 검중함에 있어 연구의 한계들이 지적 될 수 있을 것이다. 본 연구의 한계와 이에 따른 향 후 연구 방향은 다음과 같다.

첫째, 자율적인 텁 분위기는 유기적인 구조(organic structure)와 관련이 있는데 유기적인 구조와 혁신과의 관계가 긍정적(positive)이라고 주장되고 있지만 유기적인 구조가 혁신 프로젝트의 성공을 저해한다는 점도 지적된다.(Zaltman, Duncan, \& Holbek, 1973; Yap \& Souder, 1994) 유기적인 구조의 개념은 상당히 다차원적이며 조직 구조의 측면과 문화/분위기의 측면을 포함하는 복합적인 개념이다. 기존 연구의 경우 유기성의 
측면을 분위적 요소(자율성, 독립성, 참여정도)로 측정하는 경우와 권력관계 요소(위계성, 권한 집중도, 공식화)로서 측정하는 데에 따라 연구 결과의 차이를 보이고 있다. 그러므로 신제품 개발팁 내의 자율성의 개념올 확대하여 유기적인 조직 구조의 구성 차원과 이에 따른 혁신 혹은 신제품 개발과정 성과와의 인과적인 관계에 대한 연구가 필요하다 할 것이다.

둘째, 연구 모형에서 제시된 신제품 경쟁우위에서 신제품 원가효율성에 대한 측면을 고려하지 못하였다. 신제품에 대한 고객의 선호는 신제품의 구매로부터 얻는 혜택 benefit)과 비용(cost)의 비교를 통하여 이루어지기 때문에 신제품의 사용에 따르는 혜택(benefit)의 증가와 신제품의 구매에 따르는 비용의 감소가 동시에 중요한 요소이다. 품질 우수성이 고객의 혜택 측면이라면 고객의 비용은 가격일 것이다. 가격 우위는 신제품 성과에 중요한 영향올 미친다. (Cooper \& Kleinschmidt, 1987; Souder, 1987; Yap \& Souder, 1994). 그러므로 가격 우위를 달성할 수 있는 원가 효율성을 신제품 경쟁우위로 파악하고 원가 우위에 영향을 미치는 조직 학습 요인과 신제품 개발팁의 분위기 톡성과의 관계가 규명될 필요성이 있다.

쎗째, 조사 방법과 관련하여 구성 개념을 측정함에 있어 항목 수가 적어 측정의 신뢰도에 한게가 있다. 신제품 경쟁우위와 신제품 성공에 대한 경우 3 항목으로 측정되었으나 조직 학습과 분위기 요인의 경우 2항목으로만 측정이 이루어졌다. 이와 관련하여 조직 기억 organization memory)의 경우 조직 학습 이론에서는 문화, 관습, 규칙과 절차 등 사회화 과정을 통하여 조직에 내재된 개념으로 파악하고 있으나 본 연구에서 과거 정보의 데이터 배이스의 정도와 이에 대한 접근성의 정도로 파악하여 제한된 개념으로 사용하고 있다. 연구 모형에서 제시된 구성 개념에 대한 측정을 정확하게 하여 연구의 신뢰성과 타당성이 검토되어지는 것이 바람직할 것이다. 또한 넷째, 표본 단위가 신제품 개발팀이나 설문응답은 핵심 웅답자 방법으로 개인이 웅답함으로써 과거 제품 개발과정에 대한 기억에 의존하여 웅답을 유도되어진 것도 측정의 신뢰성을 저해하는 요인이 될 수 있다. 


\section{<참고 문헌>}

이 순묵(1990), 「공변량 구조 분석」, 서울: 성원사.

이 유재· 박 찬수 편역(1995), 「신상품 마케텅」, 서울: 시그마프레스.

임 종원, 김 기찬(1989), "신제품개발의 성공요인 분석," 중소기업 연구, 제 11권, 제 1호, pp. 133-162.

윤 태석(1992), "신제품 성공의 요인간 관계예 관한 연구-소비재를 중심으로-" , 서울대학교 대학원 박사학위 논문.

Abernathy, W.J. \& J.M. Utterback(1978), “Patterns of Industrial Innovation," Technological Review, June/July.

Adams, M. E., G. S. Day, \& Deborah Dougherty(1998), "Enhancing new product development performance: an organizational learning perspective," Journal of Product Innovation Management, Sept, v15, n5, p403(20).

Ancona, D.G. \& D.F. Caldwell(1992), "Bridging the boundary:External activity and performance," Administrative Science Quarterly, Dec.

Brown S. L. \& K. M. Eisenhardt (1995), "Product Development: Past Research, Present findings, and Future Direct ion, Academy of Management Review, v 20(2).

Clark, K. \& Fujimoto, T.(1991), Product Development Performance, Boston, Harvard Business School Press.

Cohen, W. M. \& D. A. Levinthal(1990), "Absorptive Capacity: A new Perspective on Learning and Innovation", Administrative Science Quarterly, 35(1), pp. 128-152.

Cooper, R.G.(1979), "The Determinant of Industrial New Product Success and Failure," Journal of Marketing, 43(Summer)

Cooper, R. G., \& E. J. Kleinschmidt(1994), "Determinants of timeliness in product development, Journal of Product Innovation Management, 11, pp.381-396.

Day, G. \& R. Wensley, (1994), "The Capabilities of Market Driven Organizations", Journal of Marketing, v 58, Oct, pp.37-52.

Dougherty, Deborah(1992), "A Practice-Centered Model of Organizational Renewal Through Product Innovation", Strategic Management Journal, Summer.

Eisenhardt, K. \& B. N. Tabrizi(1995), "Accelerating adaptive processes: product innovation in the global computer industry," Administrative Science Quarterly, March, v40, n1, p84(27).

Garud, R. \& P. R. Nayyar(1994), "Transformative capacity: continual structuring by intertemporal technology transfer," Strategic Management Journal, June, v15, n5, p365(21).

Garvin, David A.(1988), Managing Quality. NewYork: The Free Press.

Gupta, Ashok K., S.P. Raj, \& David Wilemon(1986), “A Model for studying R\&DMarketing Interface in the product development Process," Journal of Marketing, 50(April) , 7-17.

Jassawalla, A. R. \& H. C. Sashittal(1998), "An examination of collaboration in hightechnology new product development processes," Journal of Product Innovation 
Management, May, v15, n3, p237(18).

Kohli, A. K. \& B. J. Jaworksi(1990), "Market orientation: the construct, research propositions, and managerial implications," Journal of Marketing, April, v54, n2, pl(18).

Li Tiger \& Roger J. Calantone(1998), The Impact of market Knowledge Competence on New Product Advantage: Conceptualization and Empirical Examination, Journal of Market ing, v 62, Oct., pp.13-29.

Madhavan Ravindranath \& Rajiv Grover(1998), From Embedded Knowledge: New Product Development as Knowledge Management, Journal of Marketing, v 62, 0ct., pp.1-12.

Maidique, Modesto A. \& Zirger, Billie Jo(1984), "A Study of Success and Failure in Product Innovation: The Case of the U.S. Electronics Industry", IEEE Transactions on Engineer ing Management, Nov.

Mansfield E.(1988), "The speed and cost of industrial innovation in Japan and the United States: external vs. internal technology," Management Science, Oct, v34, n10, p1157(12).

McDonough, E.F.(1993), Faster New product development; Investigating the effects of technology and characteristics of the project leader and team," Journal of Product Innovat ion Managenment, 10, 241-250.

Menon, A., B.J.Jaworski, \& A.J.Kohli(1997), “Product Quality:Impact of Interdepartmental Interactions," Journal of the Academy of Marketing Science, 25( summer), 187-200.

Miles, R. E. \& Snow, C.(1978), Organizational strategy, structure and process. New York: McGraw-Hill.

Montoya-Weiss, M. M. \& R. Calantone(1994), "Determinants of new product performance: a review and meta-analysis," Journal of Product Innovation Management, Nov, v11, n5, p397(21).

Moorman, C. \& A. S. Miner(1997), "The impact of organizational memory on new product performance and creativity," Journal of Marketing Research, Feb, v34, n1, p91(16).

Morgan. N.A. \& \& N.F. Piercy(1988), “Interaction Between Market ing and Quality at the SBU Level:Influences and Outcomes," Journal of the Academy of Marketing Science, 26(summer), 190-208.

Nelson, R., \& S. Winter(1977), "In Search of Useful Theory of Innovation", Research Policy, v 6, pp.36-76.

Nonaka(1994), "Dynamic Theory of Organizational Knowledge Creation," Organization Science, v, 5, No 1, Feb. .

Ottum, B. D. \& W. L. Moore(1997), "The role of market information in new product success/failure," Journal of Product Innovation Management, July, v14, n4 p258(16). Sethi Rajesh(2000), "New product Qual ity and Product Development Teams," Journal of Market ing, 64(Apri1) , 1-14.

Shrivastava, P. (1983), "Strategic Planning for MIS, " Long Range Planning, 0ct. 16, 
16-28.

Sinkula J.M.(1994), "Market Information Processing and Organizational Learning," Journal of Marketing, v 58, Jan..

Slater S. F. \& J.C. Narver(1995), "Market Orientation and the Learning Organization, Journal of Marketing, v 59, July., pp.63-74.

Song, X. Michael \& Mark E. Parry(1997), "Teamwork barriers in Japanese hightechnology firms: the sociocultural differences between $R \& D$ and marketing managers," Journal of Product Innovation Management, Sep, v14, n5, p356(12).

Song X. Michael, Wm. E. Souder, \& Barbara Dyer(1997), "A Causal Model of the Impact of Skills, Synergy, and Design Sensitivity on New Product Performance," Journal of Product Innovation Management, 14 p.88-101.

Souder, W. E. \& X. Michael Song(1997), "Cont ingent product design and marketing strategies influencing new product success and failure in US and Japanese electronics firms," Journal of Product Innovation Management, Jan, v14, n1, p21(14).

Stalk, G. \& T.M. Hout (1990), " The Next Source of competitive Advantage," Harvard Business Review, 66(4), 31-41.

von Hippel, E.," Appropriability of innovation benefit as a predictor of the source of innovation.'" In The Economics of Innovation (ed. C. Freeman; 1982).

Walsh, J. P. \& G. R. Ungson(1991). "Organizational memory", Academy of Management Review, Jan, v16, n1, p57(35).

Yap, C. Meng \& Wm. E. Souder(1994), "Factors influencing new product success and failure in small entrepreneurial high-technology electronics firms," Journal of Product Innovation Management, Nov, v11, n5, p418(15).

Zirger, B. J. \& M. A. Maidique(1990), "A model of new product development: an empirical test." Management Science, July, v36, n7, p867(17). 